Article

\title{
Enhancement of the Localization Effect during Electrochemical Machining of Inconel 718 by Using an Alkaline Solution
}

\author{
Dengyong Wang * $\mathbb{D}$, Bin He and Wenjian Cao
}

Jiangsu Key Laboratory of Precision and Micro-Manufacturing Technology, Nanjing University of Aeronautics and Astronautics, Nanjing 210016, China; binhe06@163.com (B.H.); wjcao@nuaa.edu.cn (W.C.)

* Correspondence: dywang@nuaa.edu.cn; Tel.: +86-025-8489-6862

Received: 23 January 2019; Accepted: 15 February 2019; Published: 18 February 2019

\begin{abstract}
Electrochemical machining (ECM) is a cost-effective method for the machining of difficult-to-cut Inconel 718 superalloy. However, the machining accuracy of ECM is still limited by the poor localization effect due to the existence of stray corrosion. In this paper, a mixed solution of neutral $\mathrm{NaNO}_{3}$ and alkaline $\mathrm{NaOH}$ is used to improve the localization effect during ECM of Inconel 718. The potentiodynamic polarization curves and current efficiencies for metal dissolution are measured, and the micro morphologies are examined. The results show that the use of an alkaline solution can promote the formation of a compact passive film on the surface of Inconel 718. ECM tests with cylindrical electrodes are specially designed to verify the effect of alkaline solution on the localization of anodic dissolution. The experimental results indicated that the stray corrosion of the non-machined surface of Inconel 718 alloy can be effectively eliminated by using a mixed solution of $\mathrm{NaNO}_{3}$ and $\mathrm{NaOH}$. The surface roughness of the non-machined area can be noticeably improved.
\end{abstract}

Keywords: electrochemical machining; Inconel 718; alkaline solution; stray corrosion

\section{Introduction}

Inconel 718 is a type of nickel-based super alloy that has been widely employed in the aerospace industry because of its high-temperature strength. However, this kind of super alloy has high hardness, high cutting force, large elastic deformation and low heat conductivity coefficient. Thus, it has become one of the most typical difficult-to-cut materials in industry, and is time-consuming and high-cost to machine using traditional mechanical machining [1-3].

Electrochemical machining (ECM) is an anodic dissolution process, which can be used to remove materials efficiently regardless of the material's hardness. Compared with traditional machining methods, there is virtually no tool wear, residual stress or metallurgical defects [4,5]. Thus, ECM is especially suitable for the machining of difficult-to-cut materials and has become an important processing technology in the aerospace industry $[6,7]$.

However, the machining accuracy of ECM is greatly limited by the poor localization effect of anodic dissolution, which is generally known as stray corrosion [4]. Stray corrosion is a common phenomenon that occurs on the non-machined surface adjacent to the machining area. It will cause unwanted material removal and can lead to poor machining accuracy and surface quality to the machining part. Researchers have made many attempts to improve the localization effect of anodic dissolution in ECM. For example, the use of pulsed power has been proved to be an effective method to localize the anodic dissolution and minimize the inter-electrode gap on many occasions $[8,9]$. Auxiliary electrodes have been applied to change the electric field distribution. By eliminating the stray currents on the non-machined area, stray corrosion can be effectively reduced [10-12]. Recently, hybrid 
machining processes such as vibration-assisted ECM [13], laser-assisted ECM [14] and a combined electrical discharge machining (EDM)-ECM process [15] have also been used to obtain the desired machining accuracy.

In particular, the use of a passivating $\mathrm{NaNO}_{3}$ electrolyte is a widely-used method to improve the machining accuracy in ECM of steel, due to the passivation characteristic [16,17]. A compact passive film of several nanometers can be formed at low current density in $\mathrm{NaNO}_{3}$, and thereby hinder the metal dissolution [18]. Pa used a $\mathrm{NaNO}_{3}$ solution to obtain a smooth and bright surface in a finishing process with ultrasonic and magnetic assistance [19]. De Silva et al. used a low concentration of $\mathrm{NaNO}_{3}$ to localize the anodic dissolution in ECM [20]. Béjar and Eterovich used $\mathrm{NaNO}_{3}$ solution in a wire electrochemical cutting process to achieve more accurate cuts [21].

However, studies have also verified that the use of $\mathrm{NaNO}_{3}$ electrolyte may be ineffective in reducing stray corrosion. Due to the prominent effects of chromium, an active metal dissolution was found for the Ni-20\%Cr-Co alloys [22]. The polarization curves of cobalt also presented an active cobalt dissolution in $\mathrm{NaNO}_{3}$ solution [23]. Furthermore, the nickel-based super alloy Inconel 718 has also been found to suffer serious stray corrosion in $\mathrm{NaNO}_{3}$ solution due to the formation of a porous oxide film on the specimen surface, as reported in our previous studies [24,25].

As reported in some studies [26,27], the use of an alkaline solution can help promote the formation of a passive film on the surface during the ECM process. Thus, the use of a mixed solution of $\mathrm{NaNO}_{3}$ and $\mathrm{NaOH}$ was investigated to improve the localization effect during the ECM of Inconel 718 alloy. The potentiodynamic polarization curves and current efficiencies for metal dissolution were measured and showed that the use of an alkaline solution can help promote the formation of a compact passive film, and the anodic metal dissolution can be completely eliminated by adding a certain proportion of $\mathrm{NaOH}$ into the $\mathrm{NaNO}_{3}$ solution. ECM tests of revolution surface were also conducted to verify the effectiveness of the alkaline solution. The experimental results showed that the non-machined surface of Inconel 718 alloy can be effectively protected by a compact passive film formed in alkaline solution. The anodic dissolution can be effectively localized, and the stray corrosion was eliminated.

\section{Experimental Procedures}

\subsection{Specimen Preparation}

Inconel 718 specimens in the form of cuboids of dimensions $5 \mathrm{~mm} \times 5 \mathrm{~mm} \times 8 \mathrm{~mm}$ were used for electrochemical analysis and current efficiency measurements, and cylinders of dimensions $\Phi 200 \mathrm{~mm} \times 30 \mathrm{~mm}$ were specially prepared for the ECM tests. Inconel 718 is a type of nickel-chrome-iron alloy with some additional elements, such as $\mathrm{Nb}$, Mo and Ti [25]. Inconel 718 specimens were purchased from Shanghai Lanzhu Super Alloy Materials Company.

\subsection{Electrochemical Analysis}

The electrochemical behavior of Inconel 718 was investigated using an electrochemical workstation (R0232, Zennium E, Zahner Instruments Inc., Kronach, Germany). A platinum net and a saturated calomel electrode were prepared to be the counter-electrode and reference electrode, respectively. The cuboid Inconel 718 specimens were used as working electrodes, and all but one of the surfaces were insulated using acrylic resin glue. The linear sweep voltammetry (LSV) curves were studied in neutral $106 \mathrm{~g} / \mathrm{L} \mathrm{NaNO}_{3}$ solution, $30 \mathrm{~g} / \mathrm{L}$ alkaline $\mathrm{NaOH}$ solution and a mixed solution of $106 \mathrm{~g} / \mathrm{L} \mathrm{NaNO}_{3}$ and $30 \mathrm{~g} / \mathrm{L} \mathrm{NaOH}$.

\subsection{Current Efficiency Measurement}

In ECM, an oxygen evolution might simultaneously occur as a side reaction in parallel with the anodic metal dissolution, due to the formation of a passive film. The efficiency for anodic dissolution can reflect the localization effect for materials in ECM. Generally, large current efficiency can be obtained in a high-current-density region, leading to efficient anodic dissolution. However, to avoid 
stray corrosion, small current efficiency is expected at low current density. Thus, the current efficiencies at different current densities are essential to reflect the localization effect for anodic dissolution in ECM.

The current efficiencies for Inconel 718 at different current densities were measured on the basis of weight-loss measurements. According to Faraday's Law, the theoretical weight loss $M_{\text {theo }}$ can be calculated as follows:

$$
M_{\text {theo }}=\frac{I t}{F\left(\frac{n_{1}}{A_{1}} a_{1}+\frac{n_{2}}{A_{2}} a_{2}+\cdots+\frac{n_{j}}{A_{j}} a_{j}\right)}
$$

where $I$ is the current value, $t$ is the dissolution time, $F$ is the Faraday constant, $A_{j}$ is the atomic weight of the dissolving atoms type, and $n_{j}$ is the valence of dissolution. The valences of the metallic elements are assumed to be $\mathrm{Ni}^{2+}, \mathrm{Fe}^{2+}, \mathrm{Cr}^{3+}, \mathrm{Nb}^{3+}, \mathrm{Ti}^{4+}, \mathrm{Mo}^{4+}$ and $\mathrm{Al}^{3+}$.

A specific flow channel was designed [25], and the machining current and time were precisely controlled. To obtain the experimental weight loss $M_{\exp }$ accurately, the specimen was rinsed, dried and weighed carefully before and after each experiment. The current efficiency $\eta$ in each run can be determined to be:

$$
\eta=\frac{M_{\text {theo }}}{M_{\text {exp }}}
$$

\subsection{SEM (Scanning Electron Microscopy), EDX (Energy-Dispersive X-ray Spectroscopy)}

To examine the corroded surfaces of the Inconel 718 specimens in different solutions, scanning electron microscopy (SEM) and energy-dispersive X-ray spectroscopy (EDX) were carried out using a Hitachi S-3400N with an acceleration voltage of $20 \mathrm{kV}$.

\subsection{ECM (Electrochemical Machining) Tests of Revolution Surface}

To verify the effect of alkaline solution on the localization of anodic dissolution, ECM tests with cylindrical electrodes were specially designed. Figure 1 shows a schematic diagram of the ECM test. A cylindrical cathode tool with hollow windows was typically used. The side walls of the hollow windows were electrically insulated. During the ECM process, the anode workpiece and cathode tool were counter-rotating at the same angular velocity. With high-speed electrolytes flushing the narrow inter-electrode gap, the materials on the surface of the anode workpiece can be dissolved electrochemically, except for the corresponding areas of the hollow windows. As a result, the shapes of the hollow windows can be printed on the surface of the anode workpiece. This counter-rotating ECM method can be used in the rolling process or to machine the complex outer surface of the aero-engine casing parts $[28,29]$.

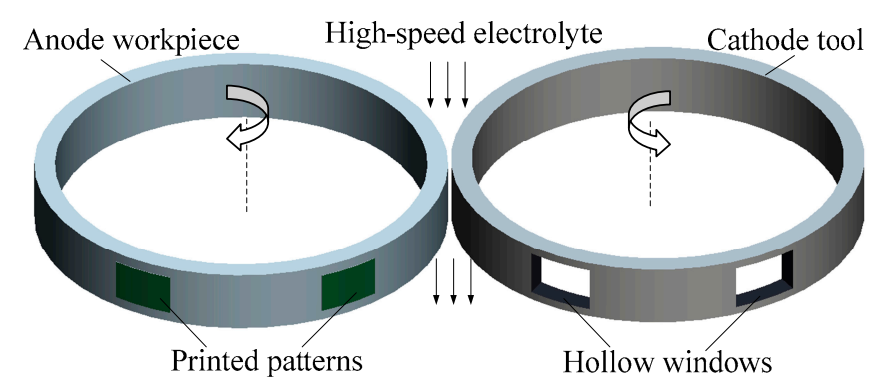

Figure 1. Principle of the electrochemical machining (ECM) test of revolution surface.

During the rotation of the electrodes, the surfaces of the printed patterns will inevitably suffer stray current attack due to the expansion of the inter-electrode gap. To obtain the current density distribution of the stray currents, the finite element method based on COMSOL 5.2 software (COMSOL Inc., Stockholm, Sweden, 2017) was used, and a proper proportion of a mixed solution of $\mathrm{NaNO}_{3}$ and $\mathrm{NaOH}$ was chosen to localize the anodic dissolution. A neutral $\mathrm{NaNO}_{3}$ solution and a mixed solution 
of $\mathrm{NaNO}_{3}$ and $\mathrm{NaOH}$ were used, respectively. The surface roughness was examined using a profile meter (M1, Mahr, Esslingen, Germany).

\section{Results and Discussion}

\subsection{Anodic Polarization Curves}

Figure 2 shows the potentiodynamic polarization curves of Inconel 718 in neutral $\mathrm{NaNO}_{3}$ solution, alkaline $\mathrm{NaOH}$ solution and a mixture of both. The potential ranges from $-2 \mathrm{~V}$ to $2 \mathrm{~V}$ with a scan rate of $1 \mathrm{mV} / \mathrm{s}$. From the variation tendencies of the current density, the anodic reactions for Inconel 718 come through the active, passive and transpassive regions in the three different solutions. The polarization curve shifts to left with increasing $\mathrm{pH}$ value of the solution. The passive region can be attributed to the formation of a passive oxidation film on the specimen surface [30]:

$$
2 \mathrm{X}+3 \mathrm{mH}_{2} \mathrm{O} \rightarrow \mathrm{X}_{2} \mathrm{O}_{\mathrm{m}}+2 \mathrm{mH}_{3} \mathrm{O}^{+}+2 \mathrm{me}^{-}
$$

The passive film can hinder the anodic reaction remarkably, leading to a decrease in the current density. From the slopes of polarization curves in the passive region, the current densities in alkaline solutions decreased faster than those in the neutral $\mathrm{NaNO}_{3}$ solution. This indicates that the use of alkaline solution can promote the formation of the passive film. In addition, when the potential is over $-0.05 \mathrm{~V}$, an obvious second passivation can be observed in the alkaline solution, from which it can be assumed that the passive oxide film is further oxidized to a higher valence state [26]:

$$
\mathrm{X}_{2} \mathrm{O}_{\mathrm{m}}+3 \mathrm{nH}_{2} \mathrm{O} \rightarrow \mathrm{X}_{2} \mathrm{O}_{(\mathrm{m}+\mathrm{n})}+2 \mathrm{nH}_{3} \mathrm{O}^{+}+2 \mathrm{ne}^{-}
$$

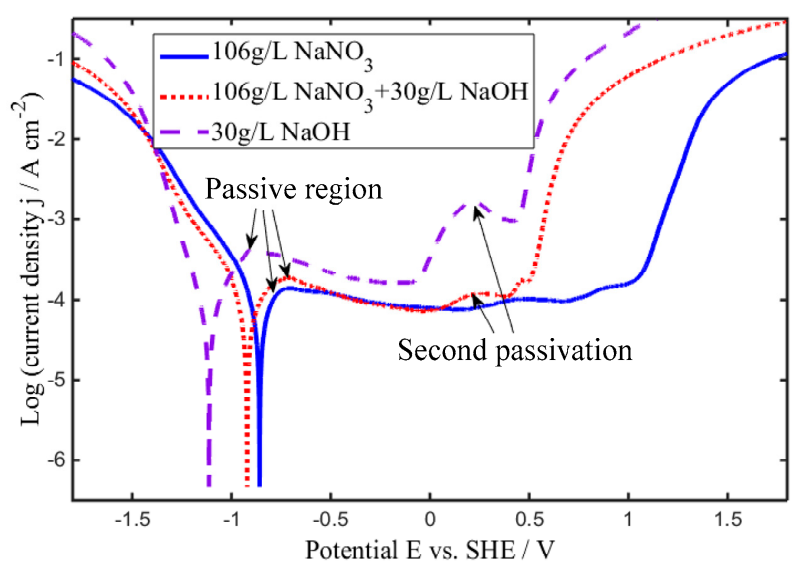

Figure 2. Potentiodynamic polarization curves of Inconel 718 in $\mathrm{NaNO}_{3}, \mathrm{NaOH}$ and a mixture of both.

\subsection{Current Efficiency of Metal Dissolution}

Figure 3 shows the current efficiencies at different current densities in the mixed solutions of $\mathrm{NaNO}_{3}$ and $\mathrm{NaOH}$. The concentration of the $\mathrm{NaNO}_{3}$ solution was $106 \mathrm{~g} / \mathrm{L}$, and the concentration of the mixed $\mathrm{NaOH}$ solution ranged from 1 to $30 \mathrm{~g} / \mathrm{L}$. The variation tendencies of the measured current efficiency are strongly dependent on the concentration of the hydroxyl. For the $106 \mathrm{~g} / \mathrm{L} \mathrm{NaNO}_{3}$ solution, a downward trend for the current efficiency was found with increasing current density. The current efficiency at low current density up to $3 \mathrm{~A} / \mathrm{cm}^{2}$ is much larger than that at higher current density, indicating serious stray corrosion occurring even at very low current density. 


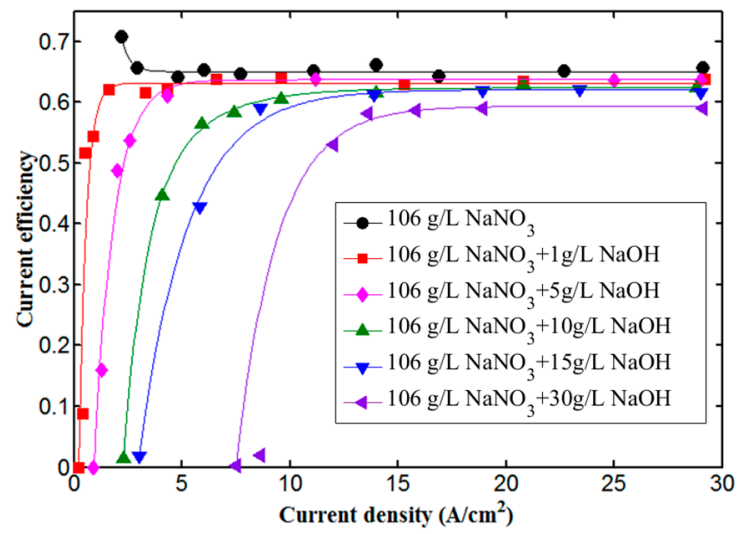

Figure 3. Current efficiency of Inconel 718 dissolution in different electrolyte solutions.

In contrast, by adding a small proportion of $\mathrm{NaOH}$ into the $\mathrm{NaNO}_{3}$ solution, the variation tendency changed dramatically. The current efficiency can be reduced to 0 at $0.2 \mathrm{~A} / \mathrm{cm}^{2}$ for a mixed solution of $106 \mathrm{~g} / \mathrm{L} \mathrm{NaNO}_{3}$ and $1 \mathrm{~g} / \mathrm{L} \mathrm{NaOH}$. This means the anodic dissolution can be completely eliminated at small current density up to $0.2 \mathrm{~A} / \mathrm{cm}^{2}$, which is favorable to localizing the anodic dissolution. When the current density was over $0.2 \mathrm{~A} / \mathrm{cm}^{2}$, the current efficiency increased rapidly with increasing current density and reached a large value of 0.62 at $1.6 \mathrm{~A} / \mathrm{cm}^{2}$. The value of $0.2 \mathrm{~A} / \mathrm{cm}^{2}$ is generally defined as the cut-off current density. For higher concentrations of $\mathrm{NaOH}$, a rightward shift can be observed for the ascending curve. When a high proportion of $30 \mathrm{~g} / \mathrm{L} \mathrm{NaOH}$ was used, the cut-off current density could be increased to $7.5 \mathrm{~A} / \mathrm{cm}^{2}$. The higher cut-off current density indicates a superior localization effect for the anodic dissolution in ECM.

\subsection{Micro-Morphology}

The Inconel 718 specimens were corroded at a current density of $5 \mathrm{~A} / \mathrm{cm}^{2}$ in $106 \mathrm{~g} / \mathrm{L} \mathrm{NaNO}_{3}$ solution and a mixed solution of $106 \mathrm{~g} / \mathrm{L} \mathrm{NaNO}_{3}$ and $30 \mathrm{~g} / \mathrm{L} \mathrm{NaOH}$. Figure 4a shows the micro-morphology of the specimen surface in $106 \mathrm{~g} / \mathrm{L} \mathrm{NaNO}_{3}$ solution. It can be seen that the specimen was seriously corroded with a solid black product film on the surface. This result agrees with the high current efficiency shown in Figure 3. According to the EDX result in Figure $4 b$, the machining products are mainly the metallic oxides and metallic carbides. The serious corrosion on the surface can be attributed to the formation of a porous oxide film in $\mathrm{NaNO}_{3}$ solution, as reported in the literature [26].

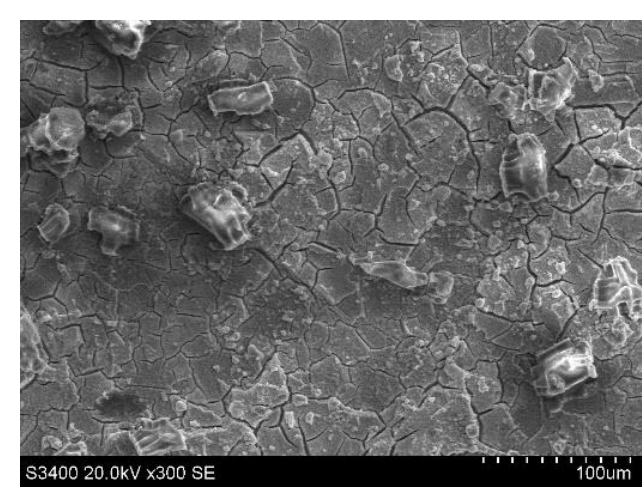

(a)

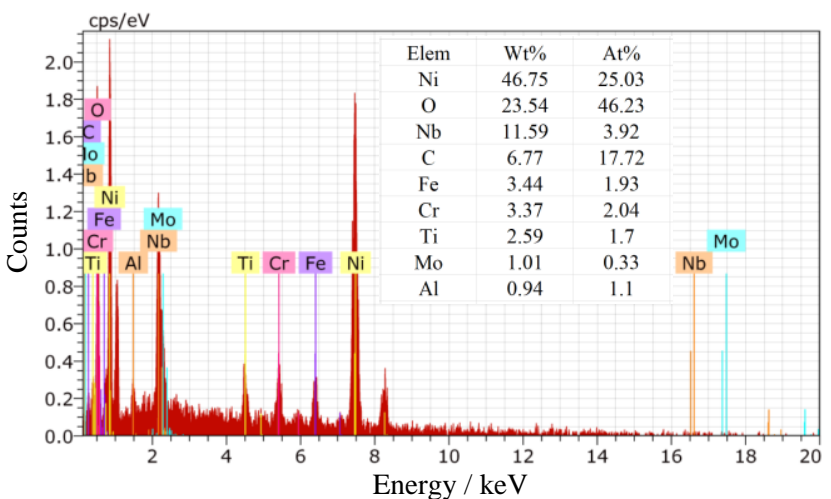

(b)

Figure 4. Scanning electron microscopy (SEM) and energy-dispersive X-ray spectroscopy (EDX) results for the corroded specimen in $106 \mathrm{~g} / \mathrm{L} \mathrm{NaNO}_{3}$ solution. (a) SEM image of the specimen surface; (b) EDX of machining products. 
In contrast, the specimen surface in a mixed solution of $106 \mathrm{~g} / \mathrm{L} \mathrm{NaNO}_{3}$ and $30 \mathrm{~g} / \mathrm{L} \mathrm{NaOH}$ is well reserved without any corrosion, and the initial topography of the surface is still visible (Figure 5a). Taking the results in Figures 2 and 3 together, a compact passive film can be assumed to have formed on the specimen surface in alkaline solution after two passivation stages. The passive film is indestructible at low current density, and thereby protected the inner materials from corrosion. From the EDX result shown in Figure $5 b$, the detected metallic element contents are consistent with the main metal compositions of Inconel 718. No significant oxygen or carbon peaks can be detected. This is because the thickness of the passive film was approximately a few nanometers [31], which is much thinner than the information depth of EDX (1-2 $\mu \mathrm{m})$ [26].

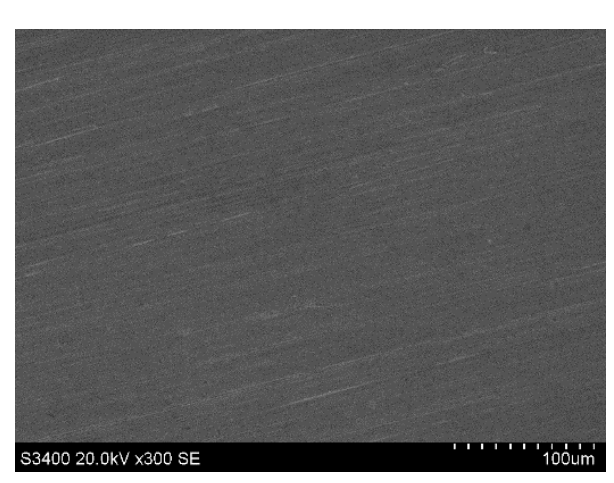

(a)

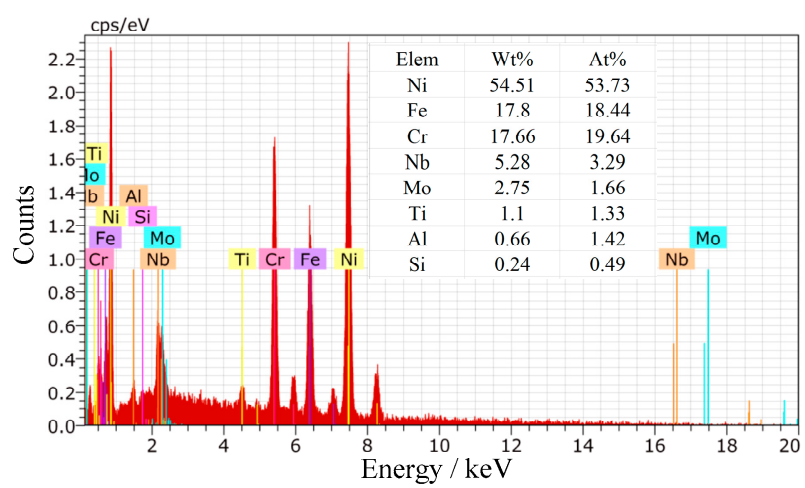

(b)

Figure 5. SEM and EDX results for the corroded specimen in a mixed solution of $106 \mathrm{~g} / \mathrm{L} \mathrm{NaNO}_{3}$ and $30 \mathrm{~g} / \mathrm{L} \mathrm{NaOH}$. (a) SEM image of the specimen surface; (b) EDX of machining products.

\subsection{ECM Results of Revolution Surface}

To avoid stray corrosion in ECM, the cut-off current density (see Figure 3) using a mixed solution of $\mathrm{NaNO}_{3}$ and $\mathrm{NaOH}$ should be higher than the maximum current density on the non-machined surface of the printed patterns. In order to choose the proper proportion of a mixed solution of $\mathrm{NaNO}_{3}$ and $\mathrm{NaOH}$ to localize the anodic dissolution, the current density distribution on the anode surface was calculated using the finite element method. As shown in Figure 6, a potential difference of $20 \mathrm{~V}$ was applied between anode workpiece and cathode tool, and the electric potential distribution $\varphi$ within the electrolyte domain satisfies Laplace's equation:

$$
\frac{\partial^{2} \varphi}{\partial x^{2}}+\frac{\partial^{2} \varphi}{\partial y^{2}}=0
$$

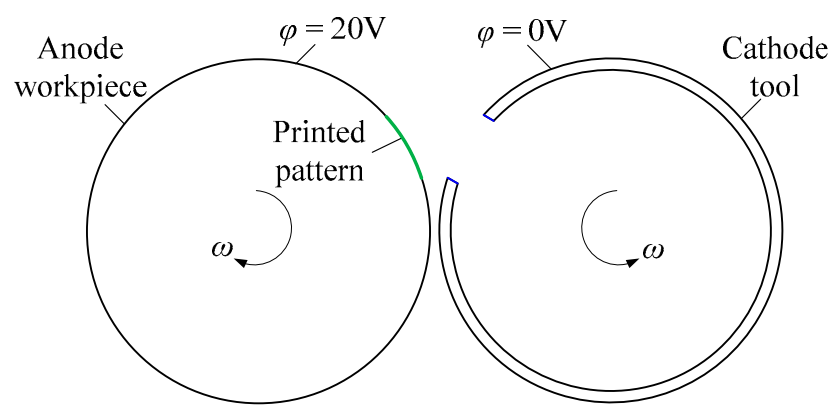

Figure 6. Numerical simulation model in cross-section.

Figure 7 shows the current density distributions on the anode surface at different rotation angles. Each line represents a current density distribution at a certain rotation angle. A valley area of the current density can be found along the arc length, which corresponds with the surface of the printed pattern. Even though the current density in the valley area is much smaller than the other sections, 
the value remains approximately $0.5 \mathrm{~A} / \mathrm{cm}^{2}$ in the center to more than $7 \mathrm{~A} / \mathrm{cm}^{2}$ in the margin area of the printed pattern. According to the current efficiency curve shown in Figure 3, the current efficiency was persistently high even at low current density in $\mathrm{NaNO}_{3}$ solution, which will lead to serious stray corrosion on the surface of the printed pattern.

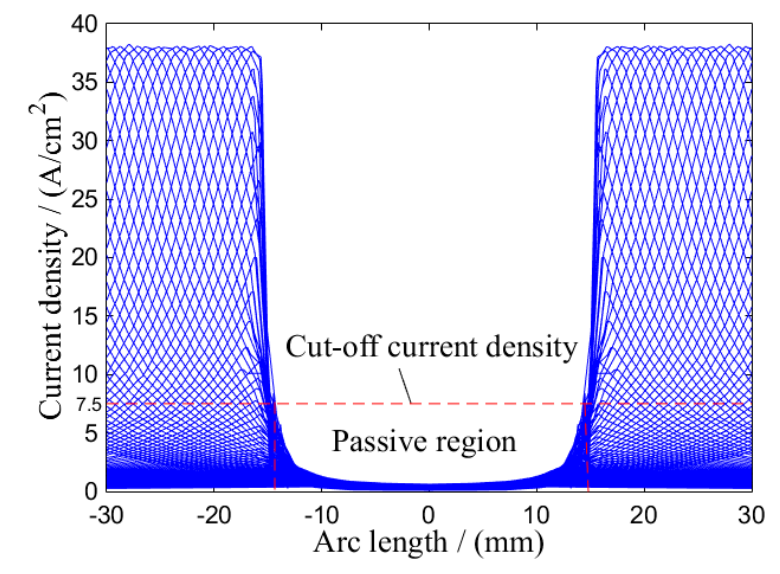

Figure 7. Current density distribution on the anode surface at different rotation angles.

Thus, a mixed solution of $106 \mathrm{~g} / \mathrm{L} \mathrm{NaNO}_{3}$ and $30 \mathrm{~g} / \mathrm{L} \mathrm{NaOH}$ is suitable, with which the cut-off current density can reach a high value of $7.5 \mathrm{~A} / \mathrm{cm}^{2}$ (Figure 3). The surface of the printed pattern can be completely passivated. The material dissolution on the non-machined surface can be effectively eliminated, and thereby the anodic dissolution in ECM can be localized accordingly.

Based on the studies above, the revolving Inconel 718 workpieces were tested during the ECM process shown in Figure 1. A neutral $\mathrm{NaNO}_{3}$ solution and a mixed solution of $106 \mathrm{~g} / \mathrm{L} \mathrm{NaNO}_{3}$ and $30 \mathrm{~g} / \mathrm{L} \mathrm{NaOH}$ were used, respectively. The machining parameters are listed in Table 1.

Table 1. Experimental parameters used in electrochemical machining (ECM).

\begin{tabular}{cc}
\hline Parameter & Value \\
\hline Applied voltage & $20 \mathrm{~V}$ \\
Electrolyte & $106 \mathrm{~g} / \mathrm{L} \mathrm{NaNO}_{3}, 106 \mathrm{~g} / \mathrm{L} \mathrm{NaNO}_{3}+30 \mathrm{~g} / \mathrm{L} \mathrm{NaOH}$ \\
Diameter of cathode tool & $200 \mathrm{~mm}$ \\
Initial minimum inter-electrode gap & $0.5 \mathrm{~mm}$ \\
Rotational speed & $10 \mathrm{rpm}$ \\
Machining time & $5 \mathrm{~min}$ \\
\hline
\end{tabular}

Figure 8 shows images of the machined surfaces in different solutions. It can be seen that the rectangular shape was printed on the surface of the anode workpiece. However, the surface of the printed pattern was seriously corroded in $106 \mathrm{~g} / \mathrm{L} \mathrm{NaNO}_{3}$ solution, leading to a rough machining surface, as shown in Figure 8a. In contrast, the initial bright rectangular shape can still be observed on the surface in the mixed solution of $106 \mathrm{~g} / \mathrm{L} \mathrm{NaNO}_{3}$ and $30 \mathrm{~g} / \mathrm{L} \mathrm{NaOH}$ (Figure 8b), indicating a favorable localization effect. The surfaces of the printed patterns were measured using a profile meter three times in different areas, and the average roughness values were obtained. As shown in Figure 9, the average roughness Ra of the surface in $\mathrm{NaNO}_{3}$ solution was as high as $2.34 \mu \mathrm{m}$ due to the serious stray corrosion. The surface roughness profile in the mixed solution of $106 \mathrm{~g} / \mathrm{L} \mathrm{NaNO}_{3}$ and $30 \mathrm{~g} / \mathrm{L} \mathrm{NaOH}$ presents a period characteristic, and the average roughness Ra was determined to be only $1.48 \mu \mathrm{m}$, which mainly depends on the initial roughness of turning. 


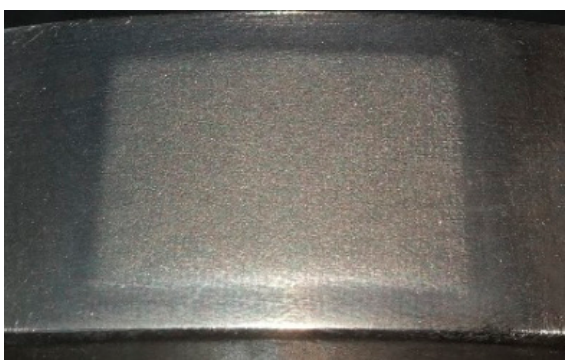

(a)

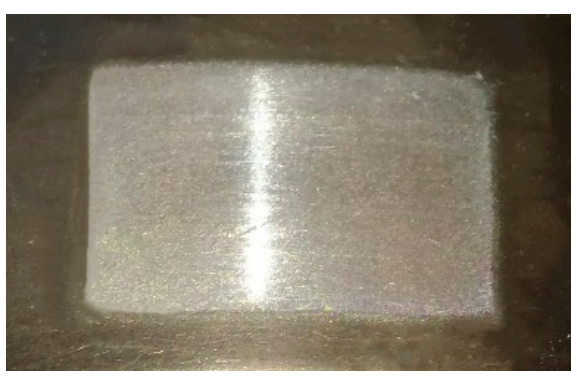

(b)

Figure 8. Images of the printed patterns in ECM. (a) $106 \mathrm{~g} / \mathrm{L} \mathrm{NaNO}_{3}$; (b) $106 \mathrm{~g} / \mathrm{L} \mathrm{NaNO}_{3}+30 \mathrm{~g} / \mathrm{L} \mathrm{NaOH}$.

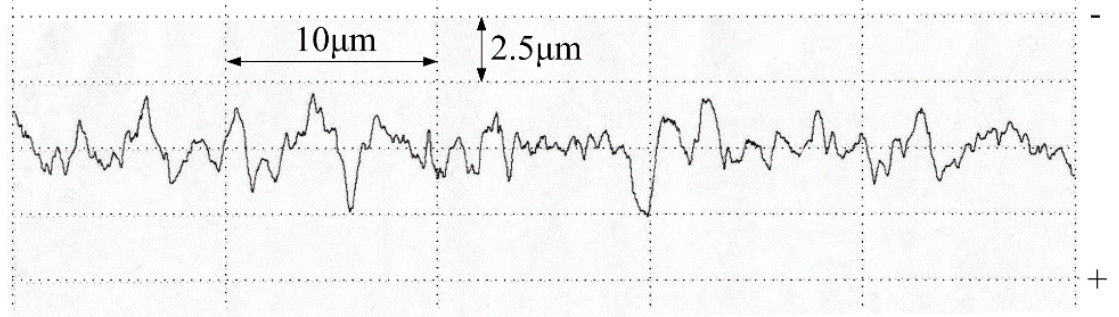

(a)

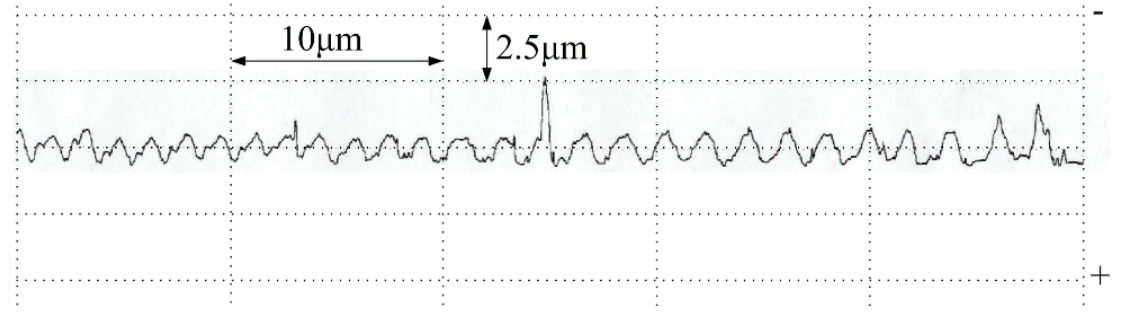

(b)

Figure 9. Measured surface roughness profiles of the printed patterns. (a) $106 \mathrm{~g} / \mathrm{L} \mathrm{NaNO}_{3}$; (b) $106 \mathrm{~g} / \mathrm{L}$ $\mathrm{NaNO}_{3}+30 \mathrm{~g} / \mathrm{L} \mathrm{NaOH}$.

\section{Conclusions}

In this paper, a mixed solution of $\mathrm{NaNO}_{3}$ and $\mathrm{NaOH}$ was used to improve the localization effect of Inconel 718 dissolution. The potentiodynamic polarization curves and current efficiencies for metal dissolution were measured, and ECM tests of revolution surface were conducted. The conclusions can be summarized as follows:

(1) Based on the potentiodynamic polarization curves of Inconel 718, the use of an alkaline solution can promote the formation of a passive film, and an obvious second passivation can be observed.

(2) According to the current efficiency curves and micro-morphologies obtained in the mixed solutions of $\mathrm{NaNO}_{3}$ and $\mathrm{NaOH}$ solution, a higher concentration of $\mathrm{NaOH}$ will lead to a superior localization effect of the anodic dissolution.

(3) The ECM results of the revolution surface verified that the stray corrosion of the non-machined surface of Inconel 718 alloy can be effectively eliminated by using a mixed solution of $\mathrm{NaNO}_{3}$ and $\mathrm{NaOH}$. The surface roughness of the non-machined area can be noticeably improved.

Author Contributions: Writing—original draft preparation, D.W.; Investigation, D.W., B.H. and W.C.

Funding: This research was funded by the China Natural Science Foundation (51805259), Foundation Research Project of Jiangsu Province (BK20180431) and the Jiangsu Key Laboratory of Precision and MicroManufacturing Technology.

Conflicts of Interest: The authors declare no conflicts of interest. 


\section{References}

1. Dudzinski, D.; Devillez, A.; Moufki, A.; Larrouquère, D.; Zerrouki, V.; Vigneau, J. A review of developments towards dry and high speed machining of Inconel 718 alloy. Int. J. Mach. Tools Manuf. 2004, 44, 439-456. [CrossRef]

2. Grzesik, W.; Nieslony, P.; Habrat, W.; Sieniawski, J.; Laskowski, P. Investigation of tool wear in the turning of Inconel 718 superalloy in terms of process performance and productivity enhancement. Tribol. Int. 2018, 118, 337-346. [CrossRef]

3. Leone, C.; D'Addona, D.; Teti, R. Tool wear modelling through regression analysis and intelligent methods for nickel base alloy machining. CIRP J. Manuf. Sci. Technol. 2011, 4, 327-331. [CrossRef]

4. Rajurkar, K.P.; Zhu, D.; McGeough, J.A.; Kozak, J.; DeSilva, A. New developments in electrochemical machining. CIRP Ann. Manuf. Technol. 1999, 48, 567-579. [CrossRef]

5. Rajurkar, K.P.; Sundaram, M.M.; Malshe, A.P. Review of electrochemical and electrodischarge machining. Proc. CIRP 2013, 6, 13-26. [CrossRef]

6. Klocke, F.; Zeis, M.; Klink, A.; Veselovac, D. Experimental research on the electrochemical machining of modern titanium- and nickel-based alloys for aero engine components. Proc. CIRP 2013, 6, 368-372. [CrossRef]

7. Dhobe, S.D.; Doloi, B.; Bhattacharyya, B. Surface characteristics of ECMed titanium work samples for biomedical applications. Int. J. Adv. Manuf. Technol. 2011, 55, 177-188. [CrossRef]

8. Wang, J.Y.; DeSilva, A.; Yu, Y.Q.; Han, G.J. New approach to enhance the accuracy of ECM high-precision short pulse ECM (HSPECM). J. Mater. Process. Technol. 2004, 149, 382-383. [CrossRef]

9. Ahn, S.H.; Ryu, S.H.; Choi, D.K.; Chu, C.N. Electro-chemical micro drilling using ultra short pulses. Precis. Eng. 2004, 28, 129-134. [CrossRef]

10. Jain, V.K.; Lal, G.K.; Kanetkar, Y. Stray current attack and stagnation zones in electrochemical drilling. Int. J. Adv. Manuf. Technol. 2005, 26, 527-536. [CrossRef]

11. Fang, X.L.; Qu, N.S.; Zhang, Y.D.; Xu, Z.Y.; Zhu, D. Improvement of hole exit accuracy in electrochemical drilling by applying a potential difference between an auxiliary electrode and the anode. J. Mater. Process. Technol. 2014, 214, 556-564. [CrossRef]

12. Wang, D.Y.; Zhu, Z.W.; Zhu, D.; He, B.; Ge, Y. Reduction of stray currents in counter-rotating electrochemical machining by using a flexible auxiliary electrode mechanism. J. Mater. Process. Technol. 2017, 239, 66-74. [CrossRef]

13. Hewidy, M.S.; Ebeid, S.J.; El-Taweel, T.A.; Youssef, A.H. Modelling the performance of ECM assisted by low frequency vibrations. J. Mater. Process. Technol. 2007, 189, 466-472. [CrossRef]

14. Pajak, P.T.; DeSilva, A.; Harrison, D.K.; McGeough, J.A. Precision and efficiency of laser assisted jet electrochemical machining. Precis. Eng. 2006, 30, 288-298. [CrossRef]

15. He, X.L.; Wang, Y.K.; Wang, Z.L.; Zhao, Q.Z. Micro-hole drilled by EDM-ECM combined processing. Key Eng. Mater. 2013, 562-565, 52-56. [CrossRef]

16. Haisch, T.; Mittemeijer, E.; Schultze, J.W. Electrochemical machining of the steel 100Cr6 in aqueous $\mathrm{NaCl}$ and $\mathrm{NaNO}_{3}$ solutions: Microstructure of surface films formed by carbids. Electrochim. Acta 2001, 47, $235-241$. [CrossRef]

17. Mao, K.W.; Hoare, J.P. The anodic dissolution of mild steel in solutions containing both $\mathrm{Cl}$ - and $\mathrm{NaNO}_{3}$-ions. Corros. Sci. 1973, 13, 799-803. [CrossRef]

18. Datta, M.; Landolt, D. Film breakdown on nickel under transpassive dissolution conditions in sodium nitrate solutions. J. Electrochem. Soc. 1971, 124, 483-489. [CrossRef]

19. Pa, P.S. Super finishing with ultrasonic and magnetic assistance in electrochemical micro-machining. Electrochim. Acta 2009, 54, 6022-6027. [CrossRef]

20. De Silva, A.K.M.; Altena, H.S.J.; McGeough, J.A. Influence of electrolyte concentration on copying accuracy of precision-ECM. CIRP Ann. 2003, 52, 165-168. [CrossRef]

21. Béjar, M.A.; Eterovich, F. Wire-electrochemical cutting with a $\mathrm{NaNO}_{3}$ electrolyte. J. Mater. Process. Technol. 1995, 55, 417-420. [CrossRef]

22. Makino, E.; Motoi, N.; Sato, T. Effects of cobalt on high rate dissolution behaviour of nickel-base superalloys in $\mathrm{NaNO}_{3}$ and $\mathrm{NaCl}$ solutions. Precis. Eng. 1983, 5, 65-72. [CrossRef] 
23. Schneider, M.; Schubert, N.; Höhn, S.; Michaelis, A. Anodic dissolution behavior and surface texture development of cobalt under electrochemical machining conditions. Electrochim. Acta 2013, 106, $279-287$. [CrossRef]

24. Wang, D.Y.; Zhu, Z.W.; Bao, J.; Zhu, D. Reduction of stray corroison by using iron coating in $\mathrm{NaNO}_{3}$ solution during electrochemical machining. Int. J. Adv. Manuf. Technol. 2015, 76, 1365-1370. [CrossRef]

25. Wang, D.Y.; Zhu, Z.W.; Wang, N.F.; Zhu, D.; Wang, H.R. Investigation of the electrochemical dissolution behavior of Inconel 718 and 304 stainless steel at low current density in $\mathrm{NaNO}_{3}$ solution. Electrochim. Acta 2015, 156, 301-307. [CrossRef]

26. Schubert, N.; Schneider, M.; Michealis, A. The mechanism of anodic dissolution of cobalt in neutral and alkaline electrolyte at high current density. Electrochim. Acta 2013, 113, 748-754. [CrossRef]

27. Doche, M.L.; Rameau, J.J.; Durand, R.; Novel-Cattin, F. Electrochemical behavior of aluminum in concentrated $\mathrm{NaOH}$ solutions. Corros. Sci. 1999, 41, 805-826. [CrossRef]

28. Wang, D.Y.; Zhu, Z.W.; Wang, H.R.; Zhu, D. Convex shaping process simulation during counter-rotating electrochemical machining by using the finite element method. Chin. J. Aeronaut. 2016, 29, 534-541. [CrossRef]

29. Wang, D.Y.; Zhu, Z.W.; He, B.; Zhu, D.; Fang, Z.D. Counter-rotating electrochemical machining of a combustor casing part using a frustum cone-like cathode tool. J. Manuf. Processes 2018, 35, 614-623. [CrossRef]

30. Sikora, E.; Macdonald, D.D. Nature of the passive film on nickel. Electrochim. Acta 2002, 48, 69-77. [CrossRef]

31. Datta, M.; Mathieu, H.J.; Landolt, D. AEX/XPS study of transpassive films on iron in nitrate solution. J. Electrochem. Soc. 1984, 131, 2484-2489. [CrossRef]

(C) 2019 by the authors. Licensee MDPI, Basel, Switzerland. This article is an open access article distributed under the terms and conditions of the Creative Commons Attribution (CC BY) license (http://creativecommons.org/licenses/by/4.0/). 